\title{
Sociologisk forskning om covid-19-pandemin
}

\author{
- en introduktion
}

\begin{abstract}
Sociological research on the Covid-19 pandemic - an introduction
A pandemic is a crisis and as such, in many ways, an entirely new situation. It is a situation in which there are scientific as well as societal uncertainties and where the routines of everyday life are overturned. The Covid-19 pandemic has made visible already established social structures and inequalities, but it has also exacerbated existing power relations and vulnerabilities. In this article, we introduce the contributions to the special issue of Sociologisk Forskning on how society and people's lives have been affected by the corona crisis and the Covid-19 pandemic. We also give an overview of some of the themes that are picked up by sociologists and social scientists internationally as well as nationally in Sweden, when trying to make sense of the meaning and effects of the Covid-19 pandemic.
\end{abstract}

Keywords: Covid-19, pandemic, expertise, trust, Sweden

\section{Sociologiska perspektiv på och forskning om coronapandemin}

Coronapandemin är en samhällskris och krissituationer innebär att relationer omprövas. Det innebär inte att allt som vi känner till eller att alla sätt vi organiserar samhället på sätts ur spel. Tvärtom är det hur samhället är organiserat som kan förklara skillnader i hur olika länder har hanterat pandemin, vilka effekter smittspridningsbegränsande åtgärder fått samt hur vi behövt omorientera oss i vår vardag. En samhällsomspännande kris innebär att många typer av relationer på olika nivåer utsätts för prövning och att dessa relationers legitimitet ifrågasätts men också förnyas och återbekräftas. Sociologiska perspektiv är bra på att belysa just detta, det vill säga hur relationer etableras, stärks, ifrågasätts och omvandlas. Sociologer har redan från början följt pandemins utveckling (Danielsson, Liljeros, Mulinari m.fl. 2020), vilket de många bidragen i detta temanummer vittnar om. Internationella Sociologförbundet har bland annat samlat artiklar på sin webbsida (ISA 2021) och olika internationella sociologiska tidskrifter har publicerat temanummer om coronapandemins effekter. Innan vi kommer in på bidragen i detta temanummer vill vi först redogöra för den bredare debatten. 
Att orsaken till pandemin kan förklaras av sociala relationer diskuteras till exempel av en del forskare i relation till globaliseringen och det faktum att våra samhällen i dag är väldigt tätt sammanvävda, vilket innebär att det som händer på en plats inte förblir ett lokalt skeende utan påverkar och sprids till många andra platser (Arias-Maldonado 2020; Tsekeris \& Zeri 2020).

På grund av pandemin och restriktionerna har vi förändrat våra relationer, vilket inneburit att många relationer som tidigare var fysiska alltmer övergått till att bli digitala; möten och utbyten sker i digitala forum och plattformar, vilket leder till nya problem med till exempel skydd av personlig integritet (Čović 2020). De förändrade relationerna mellan stat och medborgare har också belysts av forskare. De avvägningar som görs av nationella beslutsfattare mellan värden som frihet, demokrati, hälsa och ekonomi får konsekvenser som angår oss alla (Mitrovic 2020).

Att risker skapar både vinnare och förlorare är ett välkänt sociologiskt tema sedan Ulrich Becks bok Risksamhället publicerades (Beck 2000[1986]). Den nya situationen, med nedstängningar och de förändringar det inneburit, kan också skapa nya möjligheter för kriminella aktiviteter. En studie i Storbritannien analyserade de kortsiktiga effekterna av covid-19 och nedstängningar på nätbrottsligheten. Resultaten visade att antalet rapporterade så kallade cyberbrott ökade drastiskt under de två månader då nedstängningen var som striktast. Ökningen var särskilt stor för brott i samband med näthandel samt av konton på sociala medier och e-post som blev hackade (Buil-Gil, Miró-Llinares, Moneva m.fl. 2020).

Relationen mellan expertis och politik har ofta hamnat i fokus i debatten. Till exempel har den svenska regeringens åtgärder för att bromsa smittspridningen vägletts av experter inom området, men samtidigt har andra experter ifrågasatt dessa åtgärder. Olika länders hantering av pandemin kan förklaras av hur de redan har organiserat relationen mellan expertis och politik, men Meyer och Sundqvist (2020) betonar också likheterna mellan europeiska länder. Samtliga styrningsmodeller som de identifierar handlar om att medborgarna förväntas lita på experter och ta sitt ansvar, på det sätt som förväntas av dem enligt den egna nationella regeringen. Genom att belysa hur samhället redan är organiserat, så betonar Jacobsson (2020) att politisk styrning byggs upp under lång tid genom de myndigheter och den lagstiftning som är utformade för att hantera olika områden. I denna organisering ingår även politiska beslut om distansen mellan politiker och experter:

När det gäller områden där expertkunskap är viktig (exempelvis smittskydd) eller områden där det av andra skäl uppfattas som olämpligt med alltför aktiva politiker (exempelvis kultur) brukar politiker se till att "organisera sig ut ur" det dagliga beslutsfattandet. (Jacobsson 2020:7)

Expertisens roll i samhället belyses också i det pågående projekt som leds av Stephen Hilgartner och Sheila Jasanoff, professorer i teknik- och vetenskapsstudier, och som jämför 16 länders pandemihantering. Bland annat tar de upp den vanliga missuppfattningen att vetenskaplig expertis gör det möjligt för politiker att fatta de bästa besluten. 
Jasanoff och hennes medförfattare (2021) visar att vetenskapliga resultat aldrig direkt kan översättas till politiska åtgärder, de måste tolkas och avvägningar måste göras. Dessutom aktualiserar krissituationer flera typer av expertis som knappast talar med en röst. Det behöver inte innebära att expertisen är oenig, utan helt enkelt att olika former av expertis belyser olika aspekter av samma fråga.

Sociologiska perspektiv är även viktiga för att förstå maskineriet bakom produktionen av data som framställs som "rena fakta". Lidskog och Standring (2020) diskuterar de grafer och modeller över virusets spridning, antal sjuka och döda och så vidare, vilka ofta presenteras som en direkt avspegling av pandemins verkligheter. De menar att det är viktigt att förstå att dessa är resultatet av kunskapsproduktion där människor och deras beslut om hur data samlas in och presenteras också har bäring på resultaten. De fakta och figurer som presenteras kan självklart vara både giltiga och användbara, men de är sällan direkt jämförbara om de är framtagna av olika organisationer och de innebär alltid reduceringar av en mer komplex verklighet.

Relationen mellan marknadsaktörer och andra samhällsaktörer belyses av Vilhelmsson och Mulinari (2020). Pandemin kan aktualisera relationen mellan kommersiella läkemedelsföretag och allmänna intressen. Till exempel kan tilliten till offentliga myndigheter och vårdinstitutioner äventyras om uppfattningen sprids att det finns kommersiella intressen bakom de allmänna rekommendationerna till vaccinering.

\section{Bidragen i detta temanummer}

Pandemin synliggör redan etablerade strukturer och ojämlikheter i samhället, men den kan också förvärra dem. Precis som viruset letar sig fram till och förvärrar redan existerande medicinska tillstånd i enskilda kroppar, så avslöjar och förvärrar pandemin redan existerande svagheter i samhällskroppen. Där det fanns strukturella svagheter i samhällets institutioner redan innan pandemin bröt ut blir utmaningarna med att hantera viruset och dess effekter som svårast (Jasanoff, Hilgartner, Hurlbut m.fl. 2021).

Att pandemin accentuerar samhällelig ojämlikhet och utsatthet är ett återkommande tema i flera av numrets texter. I "Tid för förändring av arbetsvillkor inom vård och omsorg" beskriver Erika Wall och Jonny Bergman hur de upplevda problemen inom vården måste förstås i ett tidsperspektiv bortom det "unika i den akuta situationen" av pandemin. Problemen som uppdagat sig är i mångt och mycket "en del av, och ett uttryck för, en långvarig process och som är än mer central för att förstå den specifika situationens villkor”. I intervjuer med vårdarbetare framträder såldes ett gemensamt narrativ om strukturella brister på resurser, goda arbetsförhållanden och förberedelser inom den svenska sjukvården. Det finns således "en öppning för att förstå coronapandemin som en händelse som uppmärksammar någonting mer än arbetssituationen just nu, nämligen en kritik av arbetsvillkor inom vården över tid på en övergripande och generell nivå".

När covid-19-pandemin nådde Sverige i februari 2020 anade de som var verksamma på landets kvinnojourer vad en nedstängning av samhället skulle kunna innebära för de som lever med hot och våld i sina hem. Kristofer Hansson och Charlotte Peters- 
son vill förstå och analysera hur relationen mellan den våldsutsatta kvinnan och det gemensamma kan förstås i tider av pandemi. I artikeln "Den sårbara gemenskapen. Kvinnojourer under covid-19-pandemin" gör de detta genom en teoretisk modell för det gemensammas betydelse i tider av pandemi och belyser detta genom att låta människor som arbetar på kvinnojourerna komma till tals. Författarna diskuterar hur de livsviktiga kontaktytorna med den samhälleliga gemenskapen (Gemeinschaft) som kvinnojourerna erbjuder riskerar att krackelera. ”Genom att viruset så starkt påverkar hur samhället förväntar sig att vi ska agera som individer - för att skydda samhället från farlig smitta - påverkar det samtidigt de sårbara grupper som är i stort behov av just samhället som ett skydd", skriver de.

Att" [k]risen uppenbarar brist" skriver Clara Iversen, David Redmalm, Marie Flinkfeldt och Marcus Persson i ”En människa bland andra? Äldre människors begripliggörande av vardagen under covid-19-krisen". Författarna använder ett unikt datamaterial bestående av samtal till telefonlinjen "Äldrelinjen" som analyseras utifrån ett vardagssociologiskt ramverk. Som förväntat beskriver många inringare oro, utsatthet och utanförskap. Men författarnas analys visar också att "frånvaron av vardagen såsom den tidigare sett ut skapar eller synliggör utmaningar i sociala relationer, eftersom de inte längre kan tas för givna". I synnerhet pekar författarna på inringarnas insikter kring brist "på flexibilitet i hemtjänsten, tid och engagemang hos barn och barnbarn, och tillåtelse att vara klagande och behövande i nära relationer". Denna utsatthet i sociala relationer vill de förstå som en avsaknad av vad sociologen Harold Garfinkel benämner basal tillit: "relationer som inte går att byta ut tycks, från inringarnas perspektiv, inte tillåta anpassningar för att hantera krisens utmaningar av vardagslivets ordning".

I detta temanummer finns två bidrag som använder kvantitativa metoder för att undersöka relationen mellan tillit och oro utifrån olika enkätmaterial. Studierna visar att det finns en utbredd oro över coronapandemin i Sverige och att det främst är konsekvenserna för hälsan som driver oron. I artikeln "Oro över coronapandemin i det svenska samhället" pekar Joakim Kulin, Ingemar Johansson Sevä, Mikael Hjerm och Filip Fors Connolly på ett flertal förklaringsfaktorer som är kopplade till oro och lyfter fram människors riskuppfattningar som särskilt viktiga. Ett kanske anmärkningsvärt resultat kopplat till tillit är att ett större förtroende för forskare och sjukvården är kopplat till en högre grad av oro samtidigt som ett större förtroende för Folkhälsomyndigheten är kopplat till en lägre grad av oro. Relationen mellan tillit och oro verkar såldes bero på vilka aktörer man har störst förtroende för: forskare och sjukvården, eller Folkhälsomyndigheten.

Artikeln "Att leva med en världsomfattande pandemi. En studie om människors oro kopplat till covid-19 i Sverige" är författad av Tanya Jukkala, Sara Ferlander, Osman Aytar, Emma Engdahl, Antoaneta Hristova, Maria Hopstadius, Andrew Blasko och Vessela Misheva. Jukkala och hennes medförfattare gör en viktig distinktion mellan institutionell tillit och tillit till andra medmänniskor. Studien visar till exempel att de som uttrycker mest oro är bland annat äldre och kroniskt sjuka personer, det vill säga de som skulle vara mest utsatta om de blev smittade. Andra sociodemografiska variabler som tenderar att hänga ihop med risken att bli smittad (liksom med de ekonomiska konsekvenserna av pandemin), visade sig dock ha mindre betydelse för oro kopplat till covid-19-pandemin. 
Frågor om institutionell tillit har tydligt accentuerats i svensk debatt eftersom den svenska strategin explicit sägs bygga på svenskars starka tillit till experter och myndigheter men också experters och myndigheters tillit till svenskarnas förmåga att tillämpa rekommendationerna. Detta tema undersöks i Linda Kvarnlöfs bidrag "'Bara framtiden kan visa om vi gör det här rätt'. Att göra vardag av den svenska strategin”. Studien anlägger ett risksociologiskt perspektiv på hur människor skapar mening kring osäkerheter vad gäller betydelsen och tillämpningen av den "svenska strategin" i sin vardag. På ett generellt plan uttrycker intervjupersonerna stöd för den svenska linjen och tillit till myndigheterna och deras rekommendationer, men det finns samtidigt en underliggande kritik av hur den svenska strategin har tillämpats. Människor uttrycker stor osäkerhet inför vad rekommendationerna egentligen innebär i praktiken och hur de kan översättas till den egna vardagen. Detta kan till exempel yttra sig genom "en osäkerhet inför hur man ska bete sig när man möter människor i skogen eller huruvida man ska använda plasthandskar i mataffären eller ej”.

I artikeln "Avsked i coronatider. Att ta farväl av döende nära anhöriga i tider av restriktioner" undersöker Cathrin Wasshede och Sofia Björk vad det innebär när en nära anhörig är döende och de sörjande inte får vara fysiskt närvarande. Mer specifikt studerar författarna de dominerande föreställningar och normer kring det ideala avskedet som framkommer i intervjuer med anhöriga. Bland de drabbade anhöriga uttrycktes en stark önskan om att få vara på plats under döendeprocessen, både fysiskt och emotionellt. "Hos dem vi intervjuat som inte fick ta avsked av sina nära anhöriga på grund av restriktioner i samband med covid-19 har känslor av skuld, oro, vanmakt och djup smärta uppstått” skriver författarna. Och här dyker begreppet tillit upp igen: "Tillit till personalen är central för den empatiska föreställningen om att den anhöriga haft det bra [...] Dessa hoppfulla fantasier störs dock av mer hotfulla bilder av den anhöriga som ensam, oförstådd och plågad”. När tilliten till både personal och myndigheternas strategi brister "ökar känslor av besvikelse, maktlöshet och vrede" hos de intervjuade. För att hantera sina känslor försöker därför intervjupersoner upprätthålla tillit både till personalen och myndigheterna.

\section{Sociologiska teman i medias bevakning av pandemin}

Det är intressant att notera att de teman som belyses i de olika artikelbidragen också är teman som förekommer i medias bevakning av pandemin. Det handlar om teman som tillit, oro, ångest, osäkerhet, relationen till experter och myndigheter samt de restriktioner som sjösatts eller inte. I en korpuslingvistisk studie av medias rapportering av pandemin under 2020, av en av författarna (Susanna Öhman), framgår hur dessa teman förekommit i svensk dagspress och hur de begreppsliggjorts (Giritli Nygren, Klinga, Olofsson m.fl. 2021).

Korpusen består av 26841 artiklar där orden "covid-19" eller "corona" förekommer. Totalt består korpusen av 16487463 ord och 272568 ordtyper. Artiklarna är hämtade från tre svenska dagstidningar med olika regional spridning och politiska inriktningar: Dala-Demokraten (DD), en fristående socialdemokratisk lokal morgontidning; Svenska 
Dagbladet (SvD), en obunden konservativ morgontidning; och Aftonbladet (AB), en obunden socialdemokratisk kvällstidning. Med hjälp av AntConc, en gratis mjukvara för korpusanalys med hjälp av konkordans- och textanalys, har sökningar gjorts på ett urval av orden för att undersöka i vilka sammanhang de ingår. Detta görs genom att analysera vilka ord som finns i nära anslutning till sökorden. Varje sökning inkluderar fem ord till vänster och fem ord till höger om det aktuella ordet. Orden som har undersökts på detta sätt är: hälsa, demokrati, ekonomi, tillit, förtroende, oro och ångest. De ord som oftast förekommer i anslutning till ett sökord har listats och senare analyserats. Funktionsord som exempelvis $i, p \dot{a}, e n, a v$ och hon har tagits bort. Kollokationsanalys har använts och denna analysmetod har gjort det möjligt att analysera hur olika termer beskrivs genom att undersöka vilka andra ord som förekommer i nära anslutning till dem. För att förstå det sammanhang där orden förekommer har Giritli Nygren, Klinga, Olofsson m.fl (2021) även använt konkordansanalys. Konkordansanalys gör det möjligt att se hela meningar i vilka orden förekommer och ger därmed en djupare förståelse av diskursen.

Med hjälp av dessa metoder visar studien att ekonomi och ekonomiska konsekvenser är det dominerande temat, snarare än hälsa och demokrati. Ekonomi och ekonomiska konsekvenser förekommer i huvudsak i anslutning till företag, men också i anslutning till samhället och människor, och framstår som det dominerade temat i rapporteringen, snarare än hälsa och demokrati (Figur 1). I synnerhet gällde detta i januari innan pandemin nådde Sverige. Tittar man på hur kontexten ser ut kring ordet ekonomi så är det vanligaste en diskussion om pandemins effekter på ekonomin. Ekonomi kopplas i de allra flesta fall till "bolag" som är det ord som mest frekvent förekommer tillsammans med ekonomi.

Figur 1. Frekvensen av orden ekonomi, hälsa och demokrati i tre svenska dagstidningar (SvD, AB och DD) per månad under 2020, vägt för antalet artiklar under respektive månad.

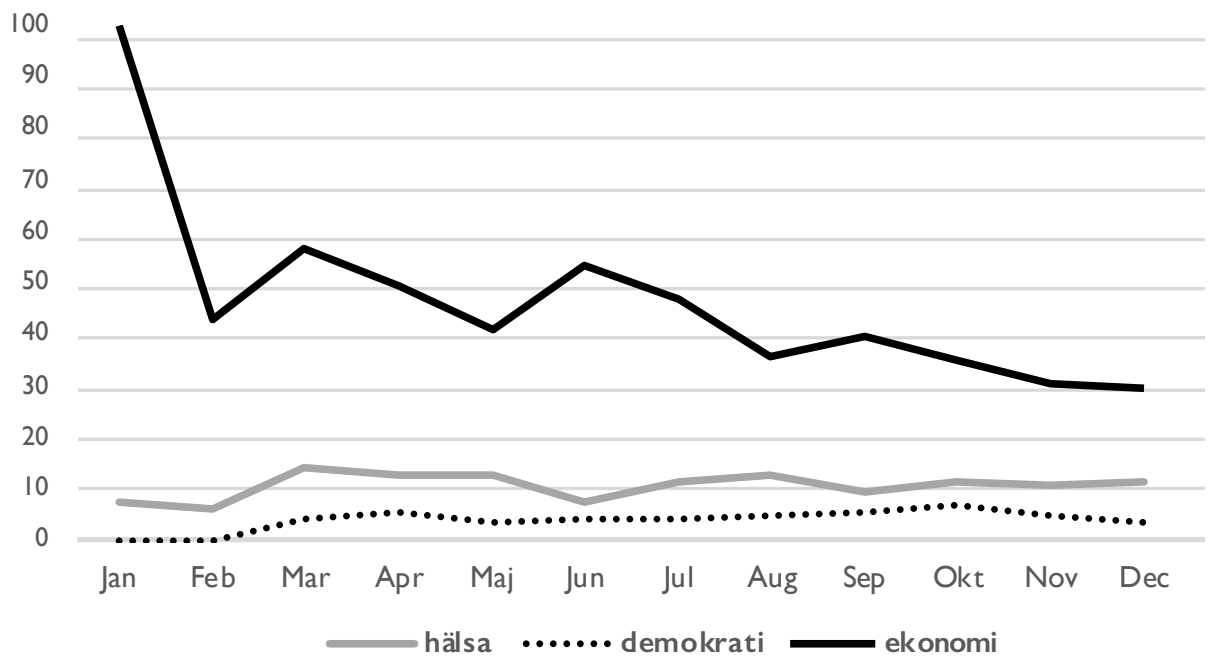


Tittar vi specifikt på de teman som diskuteras i bidragen i detta temanummer är "oro" i olika former vanligt förekommande. I början av året är det oro för ekonomin som dominerar. Viruset har inte fått fäste i Sverige och oron handlar mer om eventuella konsekvenser för den globala ekonomin. Längre fram förknippades dock oron också med hälsa, psykisk ohälsa på grund av isolering och ensamhet, och en oro för att bli smittad. Oro för våld i hemmet, dålig studiemiljö och arbetslöshet är också vanliga teman. Ångest är också förknippat främst med ensamhet och psykisk ohälsa då mångas liv plötsligt förändras i mars-april 2020 under den första vågen.

Tillit och förtroende är också teman som förekommer i dagspressen under hela 2020. Högt eller lågt förtroende för de åtgärder Folkhälsomyndigheten rekommenderar samt tillit till olika experter är förekommande ämnen i dagspressen. Sveriges linje i förhållande till andra länders är något som återfinns från mars och till årets slut. Det handlar om tillit till vårdpersonalen och deras arbete med sjuka, men också en ibland bristande tilltro till äldrevården och de resurser som krävs för att göra ett bra arbete med att begränsa smittan på boenden. Detta sätts i kontrast till Norge och Finlands låga dödstal i förhållande till Sveriges, och då särskilt i förhållande till hur väl man lyckats skydda de äldsta i samhället.

Figur 2. Frekvensen av orden oro, ångest, förtroende och tillit i tre svenska dagstidningar (SvD, $\mathrm{AB}$ och $\mathrm{DD})$ per månad under 2020, vägt för antalet artiklar under respektive månad.

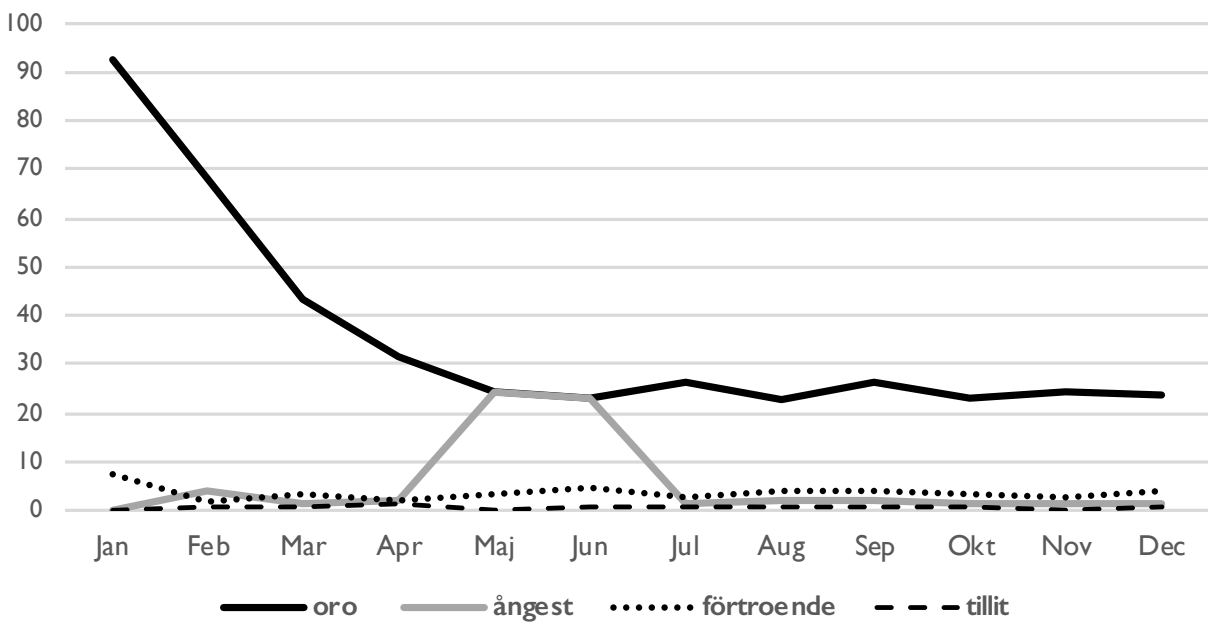

Bidragen i temanumret fångar med andra ord viktiga dimensioner som förekommer i den offentliga debatten, här representerad av artiklar i dagstidningar, och ger såldes ett viktigt kunskapstillskott till debatten i samhället. 


\section{Hur går vi vidare}

Flera av författarna i detta temanummer uppmärksammar betydelsen av fortsatta studier kring hur pandemin har skapat nya ojämlikheter. Pandemin har slagit olika i samhället och dess konsekvenser har drabbat oss på olika sätt. En studie baserad på alla registrerade covid-19-dödsfall i Sverige fram till maj 2020 visar att risken att dö i covid-19 är högre för de mest socialt och ekonomiskt utsatta grupperna i samhället (Drefahl, Wallace, Mussino, m.fl. 2020). Det mest anmärkningsvärda med denna studie är att den visar att risken att dö i covid-19 skiljer sig mer mellan svenskfödda och migranter från Mellanöstern och Nordafrika än mellan hög- och låginkomsttagare. Andra studier visar liknande resultat men menar samtidigt att vissa invandrargruppers högre risk för dödlighet i covid-19 beror på att sämre socioekonomiska villkor och levnadsstandard ökar infektionsrisken (Rostila, Cederström, Wallance m.fl. 2021). En studie av äldres risk för dödlighet i covid-19 i Sverige kom fram till att denna risk var större för de som bodde på äldreboenden än för de som bodde i oberoende hushåll, samt att de som bodde i tätbefolkade områden löpte en större risk att dö i covid-19 än de som bodde i mindre tätbefolkade områden (Brandén, Aradhya, Kolk m.fl. 2020). Det behövs fortsatt forskning kring hur grupper och individer har drabbats olika av pandemin, också med avseende på andra risker än dödlighet i covid-19, och hur det påverkar samhället framgent.

Ett annat tema som ytterligare behöver studeras är allmänhetens förhållande till experter och även hur kontroverser mellan olika typer av expertis kan förstås (Soneryd 2020). Det är ett område som studerats tidigare och som är extra viktigt att belysa under en pandemi, då frågan om experters roll och legitimitet har uppmärksammats i media och den offentliga debatten. Vi behöver analyser som kan belysa experters roll och deras relation till politik i en samhällskontext, för att undvika att debatten reduceras till enkla frågor om vilka experter som har rätt eller fel (Mulinari \& Vilhelmsson 2020).

Detta temanummer innehåller forskning som varit görbar under en begränsad tid och mitt under en pandemi. Sådana omständigheter skapar naturliga begränsningar vad gäller metoder, datainsamling och omfattning. Det finns också begränsningar relaterade till pandemins teman - exempelvis tas frågan om vaccinationer inte upp av författarna i detta nummer, eftersom studierna genomfördes innan vaccineringarna påbörjades. Studierna genomfördes under våren och sommaren 2020, före den andra vågen av pandemin och innan en rad nya restriktioner sattes in. Studierna ska ses som ett viktigt tidsdokument och som en språngbräda för vidare sociologiska studier. Vi hoppas att temanumret på så sätt kan fungera som en inspiration och att det fyller ett viktigt vetenskapligt syfte som dokumentation av sociologisk forskning under covid-19 pandemin. 


\section{Referenser}

Arias-Maldonado, M. (2020) "COVID-19 as a global risk. Confronting the ambivalences of a socionatural threat", Societies 10 (4):1-18. https://doi.org/10.3390/ soc10040092

Beck, U. (2000[1986]) Risksamhället. På väg mot en annan modernitet. Göteborg: Daidalos.

Brandén, M., S. Aradhya, M. Kolk, J. Härkönen, S. Drefahl, B. Malmberg, M. Rostila, A. Cederström, G. Andersson \& E. Mussino (2020) "Residential context and COVID-19 mortality among adults aged 70 years and older in Stockholm. A population-based, observational study using individual-level data", The Lancet 1 (2):80-88. https://doi.org/10.1016/S2666-7568(20)30016-7

Buil-Gil, D., F. Miró-Llinares, A. Moneva, S. Kemp, \& N. Díaz-Castaño (2020) "Cybercrime and shifts in opportunities during COVID-19. A preliminary analysis in the UK", European Societies 23 (supplement 1):47-59. https://doi.org/10.1080/1 4616696.2020 .1804973

Čović, A.V. (2020) "Right to privacy and protection of personal data in the age of the COVID-19 pandemic", Sociološki pregled 54 (3):670-697. https://doi.org/10.5937/ socpreg54-27284

Danielsson, E., F. Liljeros, S. Mulinari \& L. Soneryd (2020) "Sociologiska perspektiv på coronakrisen. Fyra sociologer om samhällets reaktion på covid-19", Sociologisk Forskning 57 (1):67-76. https://doi.org/10.37062/sf.57.21539

Drefahl, S., M. Wallace, E. Mussino, S. Aradhya, M. Kolk, M. Brandén, B. Malmberg \& G. Andersson (2020) "A population-based cohort study of socio-demographic risk factors for COVID-19 deaths in Sweden", Nature Communications 11:5097. https:// doi.org/10.1038/s41467-020-18926-3

Giritli Nygren, K., M. Klinga, A. Olofsson \& S. Öhman (2021) "Struggles over discursive legitimacy during the Covid-19 pandemic through the language of risk and threat in Swedish mass media”. Paper presenterat vid IV ISA Forum of Sociology, Porto Alegre, Brasilien, 23-28 februari 2021.

ISA [International Sociological Association] (2021) "Global sociology and the coronavirus. Publications and call for papers", https://www.isa-sociology.org/en/ publications/isa-digital-worlds/global-sociology-and-the-coronavirus/publicationsand-call-for-papers (hämtningsdatum 17 maj 2021).

Jacobsson, B. (2020) "Pandemi och politik: några missförstånd”, Organisation \& Samhälle nr 2 2020:4-9.

Jasanoff, S., S. Hilgartner, B. Hurlbut, O. Özgöde \& M. Rayzberg (2021) Comparative Covid response. Crisis, knowledge, politics. Interim report. Cambridge: Harvard Kennedy School.

Lidskog, R. \& A. Standring (2020) "The institutional machinery of expertise. Producing facts, figures and futures in COVID-19", Acta Sociologica 63 (4):443-446. https://doi.org/10.1177/0001699320961807

Meyer, M. \& G. Sundqvist (2020) "Sharing responsibilities, coping with the co- 
ronavirus. Why Swedish and French response strategies are not that different", Somatosphere, 20 juni 2020.

Mitrovic, V.L. (2020) "Double effects of the pandemic (corona)", Sociološki pregled 54 (3):609-626. https://doi.org/10.5937/socpreg54-27764

Mulinari, S. \& A. Vilhelmsson (2020) "Revisiting the pharmaceuticalisation of pandemic influenza using Lukes' framework of power", Sociology of Health \& Illness 42 (2):327-341. https://doi.org/10.1111/1467-9566.13006

Rostila, M., A. Cederström, M. Wallance, M. Brandén, B. Malmberg \& G. Andersson (2021) "Disparities in COVID-19 deaths by country of birth in Stockholm, Sweden. A total population based cohort study", American Journal of Epidemiology kwab057. https://doi.org/10.1093/aje/kwab057

Soneryd, L. (2020) "Expert advice in times of crisis. Transboundary risk governance and COVID-19", Toxic News, 19 juni 2020.

Tsekeris, C. \& P. Zeri (2020) "The coronavirus as a world-historic event in the digital era", Socioloskki pregled 54 (3):498-517. https://doi.org/10.5937/socpreg54-27687

Vilhelmsson, A. \& S. Mulinari (2020) "Pharmaceutical lobbying and pandemic stockpiling. A feeling of déjà vu in the Nordic countries and why the sociological perspective is crucial to understand COVID-19", Acta Sociologica 63 (4):439-442. https://doi.org/10.1177/0001699320961430

\section{Författarpresentation}

Shai Mulinari är docent i sociologi vid Lunds universitet. Han forskar om hur marknadskrafter, reglering och medicinsk vetenskap påverkar läkemedelsutveckling och läkemedelsanvändning i samhället. Han har studerat läkemedelsstrategier och reglering under svininfluensapandemin 2009 och är del av den svenska delstudien i forskningsprojektet "Comparative Covid response. Crisis, knowledge, policy (CompCoRe)", som leds av Stephen Hilgartner och Sheila Jasanoff, och som jämför 16 länders pandemihantering.

Linda Soneryd är professor i sociologi vid Göteborgs universitet. Hon forskar om risk och miljö, med ett fokus på relationen mellan experter och berörda grupper samt allmänhetens deltagande.

Susanna Öhman är professor i sociologi vid Risk and Crisis Research Centre (RCR) vid Mittuniversitetet. Hennes forskningsintressen rör främst betydelsen av risk och osäkerhet samt social stratifiering i samhället.

\section{Kontaktuppgifter}

Linda Soneryd

Institutionen för sociologi och arbetsvetenskap, Göteborgs universitet

Box 720, 40530 Göteborg

linda.soneryd@gu.se 